\title{
DA SOLUÇÃO DE CONFLITOS PRIVADOS INTERNACIONAIS PELA ARBITRAGEM
}

\author{
Anita Bortoluzzi Fleig ${ }^{1}$ \\ Tania Moura da Silva ${ }^{2}$
}

\section{RESUMO}

Este artigo apresenta estudos sobre arbitragem privada internacional, especialmente sobre causas comerciais, no Brasil. Para tanto, foi elaborada pesquisa na área da arbitragem, incluindo os tópicos mais importantes. Dessa maneira, foi possível definir o conceito de arbitragem internacional, discutir suas vantagens e desvantagens, diferenciar a arbitragem privada da pública, a ad hoc da institucionalizada. Em seguida, passou-se a discutir duas fases muito importantes para a arbitragem privada internacional: a convenção de arbitragem e a sentença arbitral. Por fim, realizou-se uma breve análise dos diversos acordos internacionais sobre arbitragem.

Palavras-chaves: Arbitragem, Solução de conflitos, Jurisdição.

\section{ABSTRACT}

This article presents studies about international private arbitration in Brasil, specially about comercial disputes. For that, it was made researchs in arbitration area, including the most important topics. In that way, it was possibile to explain the concept of international arbitration, to discuss its advantages and disadvantages, to differ private arbitration from public arbiration, to differ ad hoc arbitration from institutional arbiration. Later, a debate was held about two very important fases for international private arbitration: the arbitration agreement in writing and the arbitral awards. At the end, diferents international conventions about arbitration were analyzed.

\footnotetext{
${ }^{1}$ Contadora e Especialista em Controladoria e Finanças - UFSM/RS

${ }^{2}$ Mestre em Integração Latino-Americana - UFSM e Professora do Departamento de Ciências Contábeis da UFSM/RS
} 
Key Words: Arbitration, Dispute resolution, Jurisdiction.

\section{INTRODUÇÃO}

Os métodos para solucionar conflitos entre indivíduos vêm evoluindo gradativamente. Durante muito tempo, as divergências entre as pessoas eram decididas por um único critério: a "lei da força". Sem um órgão imparcial para julgar, os casos eram resolvidos através da autotutela ou autodefesa, pelo exercício arbitrário das próprias razões. Com a evolução intelectual do homem, passou-se adotar também a autocomposição. Ela pode ocorrer unilateralmente, através da desistência ou submissão de uma das partes, ou bilateralmente, pela transação.

Obviamente, esses meios causam insatisfação para pelo menos um dos envolvidos na contenda, o que os levou a instituir a figura imparcial do árbitro. Um árbitro "é uma pessoa possuidora da confiança mútua em quem as partes se louvam para que resolvam os conflitos." ${ }^{3} \mathrm{Na}$ antiguidade, essa função era confiada a anciãos e sacerdotes. Somente mais tarde o Estado adquiriria poderes suficientes para chamar para si a jus punitionis, criando a jurisdição e assumindo como uma de suas funções principais a justiça.

Contudo, um método não excluiu o outro, e hoje pode-se observar a existência simultânea de todos estes, seja de forma legal ou não. A Carta Magna brasileira em seu artigo $5^{\circ}, X X X I I$, assegura a onipresença do poder jurisdicional. Casos em que são permitidos a autotutela estão previstos através das figuras da legítima defesa, no Direito Penal ${ }^{4}$, e da defesa da propriedade esbulhada ou turbada, no Direito Civil $^{5}$. A autocomposição é permitida, por exemplo, através da transação ${ }^{6}$ como forma extintiva das obrigações. Por sua vez, a arbitragem possui lei própria, a de número 9307/96.

O objeto do seguinte artigo é a arbitragem privada internacional, principalmente em casos de controvérsias geradas por contratos ou relações de cunho mercantil. Especial relevância é dada para dois momentos: a

\footnotetext{
${ }^{3}$ CINTRA, GRINOVER \& DINAMARCO. Teoria Geral do Processo. São Paulo: Malheiros, 1996. p. 22.

${ }^{4}$ Código Penal, art. 25.

${ }^{5}$ Código Civil, art. 502.

${ }^{6}$ Código Civil, art. 1025.
} 
formação (convenção de arbitragem) e a resolução (laudo arbitral). Tais momentos são de importância vital para a validade e execução da arbitragem privada internacional, como poderá se observar mais adiante.

\section{A ARBITRAGEM INTERNACIONAL}

Ao contrário do que muitos pensam, a arbitragem não é um instituto novo na legislação brasileira: existia já na primeira Constituição, a de 1824. Contudo, só com a promulgação da Lei 9307/96 foi concedida à arbitragem previsão com caráter contemporâneo, capaz de ensejar o uso corrente deste meio de solução de conflitos. A lei brasileira, portanto, passa a figurar entre os vários diplomas internacionais concernentes a esta matéria, abrindo a possibilidade de torná-la uma atividade consagrada, assim como na maioria dos países do hemisfério norte. Nesses, a arbitragem corresponde pela resolução de $80 \%$ das disputas contratuais, especialmente no que tange 0 comércio internacional ${ }^{7}$.

A arbitragem internacional é aquela que busca dirimir um conflito cujas partes são domiciliadas em países diversos. Consiste numa atividade em expansão "dentro de uma economia globalizada: transformou-se em uma jurisdição de direito comum nas relações econômicas internacionais e privadas". $^{8}$

Os sujeitos internacionais possuem várias razões para recorrerem à arbitragem: esquivar-se de justiças estatais inaptas e morosas; possibilidade de realizar a arbitragem em um país neutro; optar por quem irá decidir a causa, podendo ele ser um especialista ${ }^{9}$ na área; resolver o conflito com base nas

\footnotetext{
${ }^{7}$ Conforme Garcez in: GARCEZ. A arbitragem na era da globalização. Rio de Janeiro: Forense, 1999.

${ }^{8}$ Goulene \& Racine in: CASELLA, Paulo Borba (org.). Arbitragem: a nova lei brasileira e a praxe internacional. São Paulo: LTr, 1996. p. 177.

As leis que regulamentam a profissão de administrador (Lei 4769/65) e de economista (Lei 1411/51) dispõem a competência exclusiva desses para julgar o processo arbitral cujo objeto pertença tão somente as suas áreas de atuação. A mesma preocupação não é demonstrada no Decreto-Lei 9295/46, legislação que determina o rol de atividades privativas do contador. Tal diploma não contempla como trabalho próprio do bacharel em Ciências Contábeis o arbitramento em conflitos que se restrinjam a sua área. (cfe. BECKE, Vera Luise. Arbitragem: a Contabilidade como instrumento de decisão. 3 ed. Porto Alegre: Conselho Regional de Contabilidade do Rio Grande do Sul, 2000.) Contudo, "somente as Normas Brasileiras de Contabilidade, especificamente a NBC T 13 - das Normas de Perícia Contábil, trazem a arbitragem para dentro do contexto profissional do Contador."(SILVA, Selia Gräbner da; SILVA,
} 
regras de comércio internacional, eqüidade ou costumes; afastar a publicidade, mantendo o conhecimento do litígio restrito às partes e ao árbitro; etc.

Por outro lado, há situações que dificultam a arbitragem ${ }^{10}$, podendo uma de suas principais vantagens, a celeridade, ser reduzida. As questões prejudiciais mais comuns são a complexidade do objeto do conflito e a determinação extremamente detalhista no contrato. Este último elemento deve ser prevenido através de um contrato bem redigido, feito por um profissional especializado.

Cabe lembrar aqui se trata de arbitragem interacional privada. Quando a arbitragem é realizada em pendenga cujas partes são Estados, dizse pública. No âmbito do MERCOSUL, por exemplo, a composição dos conflitos entre os Estados membros é dada por painéis arbitrais ad hoc ${ }^{11}$, conforme o Protocolo de Brasília (1991) e o Protocolo de Ouro Preto (1994). Contudo, interessa a arbitragem como forma de solucionar conflitos internacionais de cunho comercial, portanto, a arbitragem privada.

A arbitragem possui especial importância frente aos contratos internacionais de comércio. $O$ fato do direito interno dos países de cada contratante não ser, a princípio, exigível ou de aplicação compulsória, além da inexistência de uma justiça supranacional (exceto na União Européia, em que o direito comunitário sobrepõe-se ao interno), fazem do contrato a lei primeira entre as partes. Em um contrato internacional, portanto, tudo reside nele próprio. Ele está submetido apenas a vontade dos signatários.

Neste contexto, regula-se o contrato pelos costumes e normas espontaneamente geradas pela comunidade mercantil. O conjunto dessas normas não codificadas, emanadas dos usos, costumes e princípios dos entes internacionais, independente de qualquer direito nacional, denomina-se lex mercatoria. Ela é "anacional, ou seja, um direito corporativo autônomo,

Tania Moura da. Um desafio para o contador na solução de conflitos. Revista do CRCRS, $n$. 92, p. 51-2, jan./mar. 1998.)

${ }^{10}$ No Brasil, a maior dificuldade para o crescimento da arbitragem privada ainda é o desconhecimento do instituto. "(...) menos de 50\% dos contadores e empresários conhecem esses métodos alternativos de solução de conflitos."(BRONDANI, Gilbeto. Mediação e arbitragem hoje para o profissional contábil do futuro. In: CONVENÇÃO DE CONTABILIDADE DO RIO GRANDE DO SUL, 8.,2001, Gramado, Trabalhos classificados. V. 3. Porto Alegre: Conselho Regional de Contabilidade do RS, 2001. p. 99. 
decorrente do comércio internacional. (...) Trata-se de um direito uniforme, regido por normas de origem profissional ou consuetudinárias e por princípios emanados de sentenças prolatadas em juízo arbitral”"12.

Com a emergência da lex mercatoria, o desenvolvimento do comércio internacional e a dificuldade da aplicação do direito interno nestes casos, surge a arbitragem como forma mais adequada de resolução de controvérsias. A arbitragem está calcada na autonomia da vontade das partes. Ela, apesar de prevista nos ordenamentos nacionais, o que the garante legitimidade ${ }^{13}$, não está presa a esses, como acontece com a jurisdição. Ela possui a liberdade necessária para proferir decisões conforme os parâmetros criados pela comunidade mercantil internacional, consolidando a autonomia da vontade do coletivo.

\section{DA FORMAÇÃO DA ARBITRAGEM}

Para determinar a utilização da arbitragem internacional, como forma de solucionar um conflito, são regularmente adotados os mesmos procedimentos previstos em nossa legislação pátria. Contudo, aconselha-se que antes de efetuar o processo arbitral, realize-se a mediação entre as partes. A mediação também consiste numa forma de solucionar controvérsias. Porém, é conduzida por um mediador, alguém de confiança das partes que usa sua habilidade para tentar um acordo. Importa salientar que um mediador preocupa-se com o relacionamento entre as partes, objetivando descobrir o verdadeiro empenho de cada um. ${ }^{14}$ Ao contrário do árbitro ou juiz, ele não dita um laudo ou sentença, mas conduz os indivíduos para ajustarem as suas demandas, entrando em acordo.

A opção pela arbitragem deve ser expressamente declarada por ambos sujeitos, através da convenção ou pacto arbitral. Segundo a legislação

\footnotetext{
${ }^{11}$ Arbitragem avulsa ou ad hoc é aquela que as partes adotam uma metodologia própria ou criam um conjunto de regras originais, conforme o necessário, para posteriormente guiarem a solução do conflito.

${ }^{12}$ DINIZ, Maria Helena. Dicionário Jurídico. V. III. São Paulo: Saraiva, 1998.

${ }^{13} \mathrm{O}$ contrato deve estar ligado ao sistema jurídico de uma nação. Esta, então, será o seu foro internacional (segundo MURTA, Roberto de Oliveira. Contratos em comércio exterior. São Paulo: Aduaneiras, 1992.).

${ }^{14}$ VEZZULLA, Juan Carlos. Teoria e prática da mediação. Curitiba: Instituto de Mediação, 1998.
} 
brasileira $^{15}$, a convenção de arbitragem é gênero que engloba duas espécies: a cláusula compromissória e o compromisso arbitral. A primeira é feita pela inserção de dispositivo específico no contrato, representando a intenção das partes em delegar à arbitragem a solução de um conflito futuro, que ainda não existe. Com caráter abstrato, trata-se de uma promessa de compromisso ${ }^{16}$. A cláusula compromissória consiste num compromisso autônomo, ou seja, embora nulo o contrato a que se vincula, ela pode continuar a valer, e deve ser aplicada. Do mesmo modo, se nula a cláusula compromissória, pode não o ser o contrato em $\mathrm{si}^{17}$.

O compromisso arbitral é o contrato pelo qual as partes submetem ao juízo arbitral uma controvérsia específica já instalada. Possui natureza concreta, implicando numa obrigação de fazer. Nele devem estar presentes os pressupostos do art. 10 da Lei 9307/96. Certos ordenamentos, como o do Paraguai, não distinguem cláusula compromissória de compromisso arbitral, limitando-se a prever que a fonte do processo arbitral pode encontrar-se em contrato ou ato posterior ${ }^{18}$.

Enquanto o artigo 10 da Lei $9307 / 96^{19}$ dita o que deve conter o compromisso arbitral, sob pena de nulidade, o artigo 11 cita outras disposições facultativas. Dessas, algumas devem ser especialmente observadas em caso de contratos internacionais. A cláusula de escolha da lei (IV), determinando quais normas serão aplicáveis, é de extrema importância. Aconselha-se também autorizar o julgamento por eqüidade (II) e determinar termo à decisão (III). Além disto, é conveniente, para evitar mais discussões futuras, inserir um dispositivo que deixe claro qual idioma será utilizado nos procedimentos. E

\footnotetext{
${ }^{15}$ Lei $9307 / 96$, art. $3^{\circ}$.

${ }^{16}$ Caso sejam inseridos na cláusula arbitral ou compromissória os requisitos exigidos no art. 10 da lei 9307/96, fica dispensada a realização posterior de compromisso arbitral. Assim, sua natureza não será mais de uma promessa de compromisso, mas sim de uma obrigação de fazer.

${ }^{17}$ BULOS, Uadi Lammêgo: FURTADO, Paulo. A lei da Arbitragem Comentada. São Paulo: Saraiva, 1997.

${ }_{18}$ PUCCI, Adriana Noemi. A arbitragem nos países do Mercosul. Revista dos Tribunais, São Paulo, ano 86, v. 738, p. 41-55, abr. 1997.

19 “I. o nome, profissão, estado civil e domicílio das partes; II. o nome, profissão, estado civil e domicílio do árbitro, ou dos árbitros, ou, se for o caso, a identificação da entidade à qual as partes delegaram a indicação de árbitros; III. A matéria que será objeto da arbitragem; IV. O lugar em que será proferida a sentença."
} 
estipular multa para o caso de uma das partes recusar a submeter-se à arbitragem $^{20}$.

\section{ORGANISMOS INTERNACIONAIS}

No âmbito internacional existem grandes entidades especializadas na administração da arbitragem. Muitas dessas já desenvolveram regulamentos internos para o processo, praticando a arbitragem institucionalizada ${ }^{21}$. É o caso da Corte Internacional de Arbitragem da $\mathrm{CCl}$ (Câmara de Comércio Internacional), existente desde 1923 em Paris. Um dos maiores tribunais de justiça arbitral, a Corte Internacional de Arbitragem da CCI reúne mais de cinqüenta nacionalidades em seu quadro de árbitros e possui clientes em mais de noventa países distintos ${ }^{22}$.

O escopo principal da Corte Internacional de Arbitragem da CCl é a gestão da arbitragem, assegurando o bom andamento do processo. A função de julgar é exclusiva do árbitro ou tribunal a ela pertencente. A Corte não pode interferir no mérito, mesmo quando "não esteja de acordo com a solução dada ao conflito" ${ }^{23}$. Contudo, o regulamento interno prevê que antes do árbitro ou tribunal proferir o laudo arbitral, este deve ser levado a apreciação da Corte, como uma forma de controle de qualidade no serviço prestado.

Ela mantém relações e é respeitada por órgãos mundiais tais como a OMC (Organização Mundial do Comércio), a ONU (Organização das Nações Unidas) e a sua comissão que trata do direito comercial internacional, a UNCITRAL. Esta última apresentou, em 1985, uma coleção de normas para arbitragem, objetivando a harmonização do Direito Comercial internacional e a organização da arbitragem internacional. A lei-modelo da UNCITRAL é muito utilizada em várias instituições e em processos ad hoc. Países como Austrália, Bulgária, Canadá, Cingapura, Egito, Escócia e Hungria, além de várias unidades federativas dos Estados Unidos $^{24}$, incorporaram a lei-modelo da

\footnotetext{
${ }^{20}$ MURTA, 1992.

${ }^{21}$ Arbitragem institucionalizada é aquela organizada em uma instituição arbitral permanente, mantida por segmentos profissionais ou de atividade econômica. Estes organismos possuem regras procedimentais pré-estabelecidas, sob as quais a arbitragem é realizada.

22 Garcez in: GARCEZ, 1999, p.168.

23 Derains \& Nehring in: CASELLA, 1996, p. 27.

${ }^{24}$ Conforme RECHSTEINER, Beat Walter. Arbitragem privada internacional no Brasil. São Paulo: Revista dos Tribunais, 1997.
} 
UNCITRAL à sua legislação. Essa lei-modelo também inspirou a atualização das normas concernentes à matéria em muitos Estados, dentre os quais, o Brasil.

\section{DA EXIQÜIBILIDADE DO LAUDO ARBITRAL}

Possuindo a mesma eficácia de uma sentença judicial, a sentença arbitral $^{25}$ é um título executivo. Essa equiparação introduzida pela Lei 9307/96, obriga as partes a atender a decisão do árbitro, embora não seja ele responsável pela atenção das partes à sentença. Caso não seja voluntariamente executada, a parte prejudicada pode exigir na Justiça a execução forçada, através de um processo de execução.

A sentença arbitral, diferentemente da judicial, é irrecorrível. Essa característica imprime seguridade aos partícipes, evitando o adiamento da solução da contenda pela quase infinita interposição de recursos judiciais. Muito se discutiu, porém, sobre a constitucionalidade deste dispositivo. A Constituição de 1988 consagra, em seu artigo $5^{\circ}$, o princípio do duplo grau de jurisdição, garantindo o julgamento por, no mínimo, duas instâncias. Sendo a decisão arbitral irrecorrível, ela aparentemente infringiria tal princípio.

Primeiramente, deve-se levar em consideração ser, jurisdição e arbitragem, meios distintos de resolução de conflitos. Na verdade, os princípios constitucionais são respeitados pela Lei da Arbitragem quando prevê a competência do Judiciário para decretar a nulidade do laudo arbitral ${ }^{26}$. O que pretende o legislador ao tratar da irrecorribilidade da sentença arbitral é garantir o cumprimento do pacto volitivo realizado entre as partes. "O que está sendo levado em conta nesta hipótese é a extrema plausibilidade do acordo feito entre as partes, sendo inadmissível voltar atrás, exceto em casos muito determinados"27.

Dentre as várias características adquiridas pela sentença arbitral com a nova lei, a mais significativa no âmbito das relações internacionais foi a suprimir a homologação da sentença arbitral. Segundo Pedro A. Batista

\footnotetext{
${ }^{25}$ A Lei da Arbitragem trata como sinônimos laudo e sentença arbitral. Embora alguns autores, como BECKE (2000) vejam distinções entre os dois termos, aqui se adota a mesma concepção do legislador.

${ }^{26}$ Lei $9307 / 96$, art. 33.

${ }^{27}$ BULOS \& FURTADO, 1997, p. 8.
} 
Martins $^{28}$ esse era um dos maiores entraves à implementação da arbitragem no Brasil. Mesmo a sentença produzida no território nacional carecia de homologação do Poder Judiciário, o que subtraia do instituto suas virtudes de confidencialidade e celeridade.

Quanto ao laudo arbitral estrangeiro ${ }^{29}$, foi-Ihe retirado o requisito do duplo grau de homologação para a produção de efeitos. Anteriormente à Lei 9307/96, somente eram reconhecidas pelo Supremo Tribunal Federal ${ }^{30}$ as sentenças arbitrais estrangeiras homologadas pelo judiciário do país de origem. Essa exigência não advinha da antiga legislação, pois essa era omissa em relação ao assunto. A lacuna foi, então, suprida pela orientação jurisprudencial baseada na homologação de sentenças judiciais estrangeiras. Na verdade, o que se homologava não era propriamente o laudo arbitral, mas a sentença judicial que reconhecia esse.

O problema do duplo grau de homologação tornava-se mais saliente no caso de laudos proferidos em países que a legislação não previa a homologação interna. Aparentemente, essa situação surreal resolveu-se em 1978, com a decisão sobre o processo de Homologação da Sentença Estrangeira 2.486-1 ${ }^{31}$. Nessa, o STF entendeu inexigível a homologação no país de origem se a lei desse não a prever.

Em 1995 o Brasil assinou a Convenção de Montevidéu de 1979, visando assegurar o cumprimento de sentenças judiciais e laudos arbitrais de outros países cujo mérito versasse sobre direitos civis, comerciais ou trabalhistas. Contudo, o duplo grau de homologação só foi realmente extinto quando sobreveio a nova Lei da Arbitragem, preenchendo a lacuna sobre a matéria.

A parte interessada é quem deve pedir a homologação do laudo arbitral estrangeiro. Convém a adoção de certos cuidados para evitar que a homologação seja negada. Primeiramente, deve-se observar as causas de

\footnotetext{
${ }^{28}$ Martins in: GARCEZ, 1999.

${ }^{29} \mathrm{Na}$ realização de uma arbitragem internacional não se obtém necessariamente um laudo estrangeiro. Pode-se realizar um processo arbitral no Brasil entre partes de diferentes nacionalidades. Nesse caso, teria-se uma arbitragem internacional, porque as partes possuem sede em países diversos, mas a sentença não seria estrangeira, pois seria proferida em território nacional.

${ }^{30}$ De agora em diante será identificado apenas pela sua sigla, STF.

${ }^{31}$ PUCCI, 1997.
} 
rejeição previstas nos artigos 38 e 39 da Lei 9307/96. Atente-se sobre a validade da convenção de arbitragem, conforme a lei estrangeira (que deve ser apresentada pelo requerente) ou lei nacional. A incapacidade das partes, o desrespeito aos princípios do contraditório e da ampla defesa geram a nulidade do laudo arbitral. Não se pode legitimar uma arbitragem que contenha vícios, seja na sua instituição ou no decorrer do processo.

Caso o laudo arbitral estrangeiro ofenda a ordem pública nacional ou não respeite a regra de ouro da arbitragem brasileira ${ }^{32}$, o STF pode rejeita-lo de ofício. Assim, se o referido tribunal constatar a existência de qualquer uma dessas situações ele pode, sem que alguma das partes o provoque, decidir pela não-homologação. Isso não acontece com as causas de rejeição elencadas no art. 38 da Lei 9307/96, que devem ser argüidas e provadas pela parte interessada, estando somente ao alcance dessa.

Pelo tratamento igualitário entre sentenças arbitrais e judiciais concedido pelo legislador, pode-se inferir que se aplicam às primeiras os mesmos institutos e normas complementares das segundas. Nesse ponto porém, a doutrina não é pacífica, constituindo duas correntes:

1. No processo de homologação do laudo arbitral estrangeiro, devem ser aplicadas subsidiariamente regras concernentes a homologação de sentença judicial estrangeira, estejam elas no Código Civil, Código de Processo Civil ou Regimento do STF.

2. A Lei da Arbitragem, no que diz respeito à homologação de laudo arbitral estrangeiro, possui caráter excludente, não comportando a aplicação do Código Civil, Código de Processo $\mathrm{Civil}^{33}$ ou Regimento do STF.

A própria Lei da Arbitragem estabelece a competência exclusiva do STF para julgar o pedido de homologação; conseqüentemente, submete tais processos ao Regimento Interno desse. Ora, se o Código de Processo Civil, em seu art. 483, § ú, expressa claramente que a homologação de sentenças deverá seguir o Regimento Interno do STF, e se a Lei 9307/96 adota esse dispositivo, não se concebe motivo para deixar de aplicar o Regimento Interno do STF. Ainda, a posição hierárquica da Lei da Arbitragem não dá margem a

\footnotetext{
${ }^{32}$ Contida no art. $1^{\circ}$ da Lei $9307 / 96$, a regra de ouro restringe o objeto da arbitragem a direitos patrimoniais disponíveis.

${ }^{33}$ Exceto arts. 282, 483 e 484 desse.
} 
qualquer conflito entre ela e o Código Civil ou o Código de Processo Civil, podendo, sim, essas legislações serem aproveitadas subsidiariamente.

Outros motivos levam a crer que a segunda corrente não é razoável. Deixando de aplicar o Regimento Interno do STF, a homologação da sentença arbitral seria impossível: faltaria ao processo a determinação do rito e do procedimento. Também, poderia acontecer o absurdo: homologar uma sentença arbitral estrangeira que não constituísse coisa julgada ${ }^{34}$. Contudo, pela aplicação do Regimento Interno do STF, art. 217, III, a sentença deve ter passado em julgado e cumprir todos requisitos que a tornem exeqüível no país de origem.

Assim, pode-se concluir que as normas a serem aplicadas para o reconhecimento de sentença arbitral estrangeira provém, primeiramente, da Lei 9307/96. Aplicam-se em seguida: a Convenção de Montevidéu de 1979, o Código Civil, o Código de Processo Civil e o Regimento Interno do STF.

\section{ACORDOS INTERNACIONAIS SOBRE ARBITRAGEM}

São muitos os tratados que se referem à arbitragem privada. Especialmente aqueles dedicados à regulamentação do comércio internacional costumam conter artigos incentivando a adoção da arbitragem como meio de resolução de disputas. Contudo, os acordos que versam especificamente sobre a arbitragem são mais raros. Os principais acordos internacionais sobre arbitragem privada são:

1. Protocolo de Genebra sobre cláusulas arbitrais. Estabelecido em 24 de setembro de 1923, tem como objetivo principal conferir validade à convenção de arbitragem realizada entre as partes dos países signatários. Apesar do Protocolo ter sido remetido ao legislativo brasileiro em 1929, só em 1932, através do Decreto 21.187, foi ratificado. Seu reconhecimento, portanto, aconteceu durante o governo de Getúlio Vargas e sem a efetiva participação parlamentar.Tal fato gerou muitas dúvidas quanto à validade interna do Protocolo. A jurisprudência da época aplicava-o só em casos internacionais.

\footnotetext{
${ }^{34}$ Os arts. 38 e 39 da lei 9307/96 não exigem o requisito do trânsito em julgado para concessão da homologação da sentença. Assim, contanto que a justiça do país de origem da sentença não tenha retirado-Ihe seus efeitos, anulando ou suspendendo, ela poderia ser reconhecida no Brasil.
} 
Atualmente, o Protocolo de Genebra de 1923 possui pouca relevância na prática, tanto no Brasil como no exterior.

\section{Convenção de Genebra para execução de sentenças arbitrais} estrangeiras. Também conhecida como Convenção de Genebra de 1927, determina o reconhecimento de sentenças arbitrais estrangeiras advindas de processos iniciados pelas convenções arbitrais referidas no Protocolo de Genebra de 1923. O Brasil não é signatário dessa Convenção.

\section{Convenção para o reconhecimento e execução de sentenças} arbitrais estrangeiras - Convenção de Nova York de 1958. Promovida pelas Nações Unidas, é, até hoje, o grande pilar da arbitragem internacional privada. Para os Estados signatários desta convenção estão revogados, expressamente, o Protocolo de Genebra de 1923 e a Convenção de Genebra de 1927. Lamentavelmente, o Brasil não aderiu a esta convenção, embora muitos teóricos ainda alimentem a esperança de que o faça.

\section{Convenção Interamericana sobre Arbitragem Comercial} Internacional - Convenção do Panamá de 1975. Realizada entre os Estados membros da $O E A^{35}$, visa garantir a utilização da arbitragem para solução de conflitos nascidos em relações mercantis. O Brasil só ratificou a Convenção do Panamá de 1975 mais de vinte anos após sua abertura, através do Decreto Legislativo $n^{\circ}$ 60. Com isso, todos os países integrantes do Mercosul passaram a figurar em tal Convenção, fato muito importante para o progresso da arbitragem privada internacional nestes.

\section{Convenção Interamericana sobre eficácia extraterritorial de} sentenças e laudos arbitrais estrangeiros - Convenção de Montevidéu de 1979. Também celebrada no âmbito da OEA, é complementar à Convenção do Panamá. Tem como objeto a cooperação judiciária entre os países signatários, garantindo a execução de sentenças judiciais e laudos arbitrais estrangeiros.

Existem ainda outros acordos internacionais sobre arbitragem tais como: Convenção Européia sobre Arbitragem Comercial Internacional (1961), Convenção de Moscou (1972), Convenção de Washington ${ }^{36}$ (1965), Protocolo

\footnotetext{
${ }^{35}$ Organização dos Estados Americanos.

${ }^{36}$ Também chamada de Convenção sobre Resolução de Disputas sobre Investimentos entre Estados, ou Convenção de BIRD (cfe. SILVA, Selia Gräbner da; SILVA, Tania Moura da. Perspectivas da arbitragem frente aos mercados internacionais com enfoque ao Mercosul. Revista do CRCRS, n. 88, p. 40-5, jan./mar. 1997.)
} 
de Brasília (1991) e o Protocolo de Ouro Preto (1994). Contudo, esses acordos não dizem respeito ao objeto deste trabalho já que os dois primeiros são restritos a países integrantes da antiga Comunidade Européia e do Bloco do Conselho para Mútua Assistência Econômica da Europa Oriental ${ }^{37}$; enquanto os três últimos versam sobre arbitragem pública.

\section{CONCLUSÃO}

A arbitragem é um modo de solucionar conflitos existentes há muitos séculos. Com o desenvolvimento das instituições de direito e da atividade mercantil, além do crescimento do número de controvérsias, os ordenamentos jurídicos mais modernos têm se preocupado em disciplinar a arbitragem. Assim foi com o Brasil em 1996, ao promulgar a Lei 9307.

Tal dispositivo vem a facilitar muito a aplicação da arbitragem privada internacional. A resolução de divergências de maneira especializada, segura e célere é o principal motivo da sua ampla aplicação, principalmente em relações de comércio exterior. Além disso, a possibilidade de julgar a causa conforme os costumes do comércio e a lex mercatoria otimiza os resultados obtidos pela arbitragem.

Para a realização do processo arbitral em disputas privadas internacionais é muito importante observar os requisitos de validade do compromisso arbitral, presentes no art. 10 da Lei 9307/96. Após obtida a sentença arbitral é preciso verificar sua eficácia: se ela é nacional, equivale a uma sentença judicial e pode ser executada de imediato; se estrangeira, deve ser homologada pelo Superior Tribunal Federal.

Para o futuro, prevê-se o crescimento da arbitragem internacional, principalmente a institucional ${ }^{38}$, já que a existência prévia de um regulamento sobre procedimentos facilita e imprime maior segurança às partes. A tarefa maior dos profissionais da arbitragem, especialmente os contadores, e redatores de contratos é trabalhar sobre o tema, a fim de prover melhor assessoria a quem procura resolver seus conflitos.

\footnotetext{
${ }^{37}$ Cfe. Garcez in: GARCEZ, 1999.

${ }^{38}$ Cfe. Garcez in: GARCEZ, 1999.
} 


\section{BIBLIOGRAFIA}

BASSO, Maristela. Contratos internacionais do comércio. 2 ed. Porto Alegre: Livraria do Advogado, 1998.

BECKE, Vera Luise. Arbitragem: a contabilidade como instrumento de decisão. 3 ed. Porto Alegre: Conselho Regional de Contabilidade do Rio Grande do Sul, 2000.

BRONDANI, Gilberto. Mediação e arbitragem hoje para o profissional contábil do futuro. In: CONVENÇÃO DE CONTABILIDADE DO RIO GRANDE DO SUL, 8., 2001, Gramado, Trabalhos classificados. V. 3. Porto Alegre: Conselho Regional de Contabilidade do RS, 2001.

BULOS, Uadi Lammêgo; FURTADO, Paulo. Lei da arbitragem comentada. São Paulo: Saraiva, 1997.

CASELLA, Paulo Borba (org.). Arbitragem: a nova lei brasileira e a praxe internacional. São Paulo: LTr, 1996.

Contratos internacionais e direito econômico no MERCOSUL. São Paulo: LTr, 1996.

CINTRA, Antônio Carlos de Araújo; GRINOVER, Ada Pellegrini; DINAMARCO, Cândido R. Teoria geral do processo. 12 ed. São Paulo: Malheiros, 1996.

DINIZ, Maria Helena. Dicionário jurídico. V. III. São Paulo: Saraiva, 1998.

GARCEZ, José Maria Rossani (org.). A arbitragem na era da globalização. 2 ed. Rio de Janeiro: Forense, 1999.

GRANADEIRO, Cláudia. Justiça Privada. Revista Veja, São Paulo, ano 34, n. 45, p. 136-137, 14 nov. 2001.

KLAVA, Luis Fernando. Câmaras de arbitragem e mediação ganham espaço. Gazeta Mercantil, Rio de Janeiro, 17 out. 2001. Por Conta Própria, p. 06.

MORAIS, Jose Luis Bolzan de. Mediação e arbitragem: alternativas à Jurisdição. Porto Alegre: Livraria do Advogado, 1999.

MURTA, Roberto de Oliveira. Contratos em comércio exterior. São Paulo: Aduaneiras, 1992.

PUCCI, Adriana Noemi. A arbitragem nos países do Mercosul. Revista dos Tribunais, São Paulo, ano 86, v. 738, p. 41-55, abr. 1997.

SILVA, Selia Gräbner da; SILVA, Tania Moura da. Perspectivas da arbitragem frente aos mercados internacionais com enfoque ao Mercosul. Revista do CRCRS, Porto Alegre, v. 26, n. 88, p. 40-45, jan./mar. 1997.

. Um desafio para o contador na solução de conflitos. Revista do CRCRS, Porto Alegre, v. 27, n. 92, p. 51-52, jan./mar. 1998. 
VEZZULA, Juan Carlos. Teoria e prática da mediação. Curitiba: Instituto de Mediação, 1998.

WARAT, Luis Alberto. O ofício do mediador. V. I. Florianópolis: Habitus, 2001. 